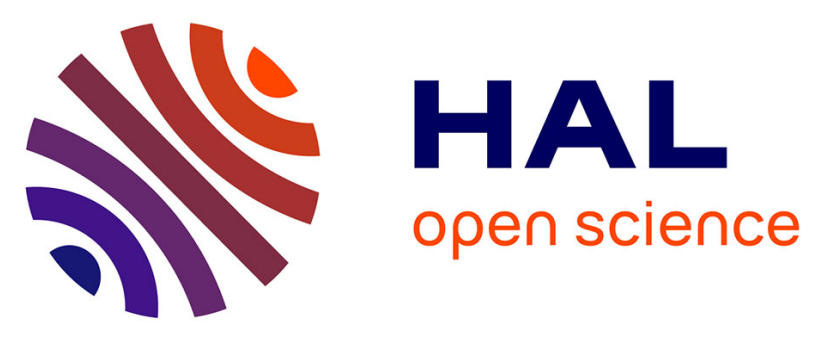

\title{
Optimal conditions for two-point estimation of self-diffusion coefficients through rf gradient NMR experiments
}

Jerome Bedet, Daniel Canet, Sebastien Leclerc, Pierre Mutzenhardt, Didier Stemmelen, Gregory Trausch

\section{To cite this version:}

Jerome Bedet, Daniel Canet, Sebastien Leclerc, Pierre Mutzenhardt, Didier Stemmelen, et al.. Optimal conditions for two-point estimation of self-diffusion coefficients through rf gradient NMR experiments. Chemical Physics Letters, 2005, 408 (4-6), pp.237-240. 10.1016/j.cplett.2005.04.026 . hal-00125035

\section{HAL Id: hal-00125035 \\ https://hal.science/hal-00125035}

Submitted on 29 May 2017

HAL is a multi-disciplinary open access archive for the deposit and dissemination of scientific research documents, whether they are published or not. The documents may come from teaching and research institutions in France or abroad, or from public or private research centers.
L'archive ouverte pluridisciplinaire HAL, est destinée au dépôt et à la diffusion de documents scientifiques de niveau recherche, publiés ou non, émanant des établissements d'enseignement et de recherche français ou étrangers, des laboratoires publics ou privés.

\section{(ㅇ)(1) $\$$}

Distributed under a Creative Commons Attribution - NonCommercial - NoDerivatives| 4.0 


\title{
Optimal conditions for two-point estimation of self-diffusion coefficients through rf gradient NMR experiments
}

\author{
J. Bedet $^{\text {a),b) }}$, D. Canet ${ }^{\text {a)* }}$, S. Leclerc ${ }^{\text {a),b) }}$, P. Mutzenhardt ${ }^{\text {a) }}$, D. Stemmelen ${ }^{\text {b) }}$, G. Trausch ${ }^{\text {a) }}$ \\ ${ }^{a)}$ Méthodologie RMN (UMR 7565 CNRS-UHP), Université Henri Poincaré, Nancy I, B.P. 239 \\ 54506-Vandoeuvre-les-Nancy (cedex), France \\ ${ }^{b)}$ LEMTA (UMR 7563 CNRS-INPL-UHP), B.P. 160 \\ 54504-Vandoeuvre-les-Nancy (cedex), France
}

* corresponding author, E-mail : Daniel.Canet@rmn.uhp-nancy.fr

\begin{abstract}
:
We address the problem of measuring accurately and as quickly as possible a self-diffusion coefficient by the so-called pulsed gradient stimulated echo experiment or, equivalently, by using a sequence involving radio-frequency field gradients. The discussion deals with the smallest diffusion coefficient which can be measured with a reasonable accuracy, possibly taking into account the values of longitudinal and transverse relaxation times along with the nature of gradients. It is shown theoretically and experimentally that the diffusion coefficient can be measured accurately via only two experiments provided that the ratio of the signal amplitudes lies in the range 0.2-0.6.
\end{abstract}


Classically, self-diffusion coefficients have been measured by NMR using the PGSE (Pulsed Gradient Spin Echo) method [1] which employs two gradient pulses of duration $\delta$ inserted on each side of the $\pi$ pulse in a spin echo sequence (see figure 1a, where gradients of the static magnetic field $B_{0}$ are employed). Many alternatives to this simple experiment were proposed with the objective to improve the quality of spectra [2, 3]. Denoting by $\Delta$ the separation between the two gradient pulses, by $\tau$ half the echo-time, and by $g$ the gradient strength, one has for the measured signal

$$
S_{P G S E}\left(g^{2}\right)=S_{0} \exp \left(-2 \tau / T_{2}\right) \exp \left(-\gamma^{2} g^{2} \delta^{2} D \Delta\right)
$$

$S_{0}$ is the signal amplitude obtained after a simple $\pi / 2$ read pulse, $\gamma$ the gyromagnetic ratio of the considered nucleus, $T_{2}$ the transverse relaxation time and $D$ the diffusion coefficient. Moreover, it has been implicitly assumed in (1) that $\Delta$ is much greater than $\delta$. However, because in many systems the transverse relaxation time $T_{2}$ may be much shorter than the longitudinal relaxation time $T_{1}[4]$, the stimulated echo (STE) method, depicted in figure $1 \mathrm{~b}$, is generally preferred [5]. Disregarding again the short periods during which the gradient pulses are applied to transverse magnetization and recognizing that, during the diffusion interval, the nuclear magnetization of interest is longitudinal, the measured signal is now of the form

$$
S_{S T E}\left(g^{2}\right)=\left(S_{0} / 2\right) \exp \left(-\Delta / T_{1}\right) \exp \left(-\gamma^{2} g^{2} \delta^{2} D \Delta\right)
$$

As indicated above, such an experimental procedure is generally more suitable as far as signal attenuation by relaxation phenomena is concerned.

It has been known for some time that self-diffusion coefficients can also be measured using gradients of the radio-frequency field ( $B_{1}$ gradients) [6]. The easiest experimental procedure [7], depicted in figure 1c, is formally analogous to the STE method so that, if gradient periods are not considered, equation (2) still applies. 
Several approaches have been proposed to reduce the number of experiments necessary for measuring self diffusion coefficients. For instance, one method uses both spin echo and stimulated echo [8] while, in another [9], the Carr-Purcell-Meiboom-Gill pulse train (employed generally for measuring the transverse relaxation train) is modified. Here, we shall limit ourselves to the STE method (or to the $B_{1}$ gradient procedure) and we shall try to determine the self-diffusion coefficient from only two measurements which differs by the two gradient strengths, $g_{1}$ and $g_{2}$. One has

$$
\begin{aligned}
& S_{1,2}=\left(S_{0} / 2\right) \exp \left(-\Delta / T_{1}\right) \exp \left(-p_{1,2} D\right) \\
& \text { with } p_{1,2}=\gamma^{2} g_{1,2}^{2} \delta^{2} \Delta
\end{aligned}
$$

with $p_{1,2}=\gamma^{2} g_{1,2}^{2} \delta^{2} \Delta$

which leads to

$$
D=\frac{1}{p_{2}-p_{1}}\left(\ln S_{1}-\ln S_{2}\right)
$$

The problem is now to determine the relative uncertainty on the determination of $D$, denoted in the following by $\partial D / D$. In the forthcoming discussion we shall further assume that $S_{1}$ is close to the maximum, meaning that $g_{1}$ is relatively weak. In a general way, one has

$$
\partial D / D=\frac{1}{S_{1}} \frac{\left(S_{1} / S_{2}+1\right)}{\ln \left(S_{1} / S_{2}\right)} \partial S
$$

where $\partial S$ is the uncertainty on the measurement of both signals $S_{1}$ and $S_{2}$. Clearly, the function $f(r)=\frac{(r+1)}{\ln (r)}$ with $r=S_{1} / S_{2}$ has to be minimized. It is plotted in figure 2 from which it is apparent that the signal corresponding to the second experiment must lie in the range $20 \%-60 \%$ of the signal which would be obtained at zero gradient. This puts a lower limit for the gradient strength with respect to the diffusion coefficient to be measured.

$$
g_{\min }=\frac{1.6}{\gamma \delta \sqrt{D \Delta}}
$$


The above considerations have been verified by proton experiments which were carried out on octanol at $23^{\circ} \mathrm{C}$ with a Bruker DRX 300 spectrometer equipped with a homemade probe possessing $\mathrm{B}_{1}$ gradient facilities. About 20 measurements were performed according to the sequence of figure $1 \mathrm{c}$ for gradient values ranging from 3.9 up to $31 \mathrm{G} / \mathrm{cm}$ (gradient strength has been calibrated by means of a series of conventional experiments on a water sample, each of them corresponding to a different output of the power amplifier feeding the $B_{1}$ gradient coil). Results of the determination of self-diffusion coefficients $D$ according to the method described in the previous section are displayed in figure 3. Each data point (except the first one) of the decay curve (denoted $S_{2}$ ) is actually compared to the experiment performed with the smallest gradient strength (which provides $S_{1}$ ) in order to deduce $D$ through equation (4). It can be seen that the relative error on $D$ is small (and quite acceptable) provided the ratio $S_{2} / S_{1}$ is between 0.2 and 0.6 (as predicted by the theory) and that the plot of deviations with respect to the expected value is qualitatively the same as the error curve shown in figure 2 . These results validate therefore the new procedure.

The next step was to check this procedure under extreme relaxation conditions. This was achieved with a sample of water doped with $\mathrm{CuSO}_{4}$ in such a way that the two relaxation times $T_{1}$ and $T_{2}$ drop toward ca. $2 \mathrm{~ms}$ (see figure 4). This means that the diffusion interval $\Delta$ must be shortened and becomes of the same order of magnitude as the gradient pulse duration $\delta$, since the latter must lie around one or several milliseconds due to the available values of the gradient strength (and the necessity that each gradient pulse completely defocuses the sample nuclear magnetization). In addition, relaxation takes place during gradient pulses according to $T_{2}$ if $B_{0}$ gradients are employed or to $T_{2 \rho}$ in the case of $B_{1}$ gradients, with $1 / T_{2 \rho}=(1 / 2)\left(1 / T_{1}+1 / T_{2}\right)$, so that formula (3) must be substituted by $\left(T_{2 \rho}\right.$ possibly in place of $T_{2}$ according to the nature of the gradients employed) 


$$
\begin{aligned}
& S_{1,2}=\left(S_{0} / 2\right) \exp \left(-\Delta / T_{1}\right) \exp \left(-2 \delta / T_{2}\right) \exp \left(-p_{1,2} D\right) \\
& \text { with } p_{1,2}=\gamma^{2} g_{1,2}^{2} \delta^{2}(\Delta+2 \delta / 3)
\end{aligned}
$$

As can be seen from figure 4, measurements are still possible even using the strategy defined above (two appropriate data points to determine $D$ ) provided that $\Delta$ is not too long with respect to $T_{1}$ (in practice, one should not exceed $3 T_{1}$ ) and that $\delta$ is lower than $2 T_{2}$.

We have thus defined the limits beyond which self-diffusion coefficient determinations become dubious. Moreover, we have shown in this paper that, rather than a complete decay curve, a properly chosen experiment (yielding amplitude in the $20 \%-60 \%$ range with respect to a reference spectrum) is quite sufficient for deducing an accurate value of the self-diffusion coefficient. Finally, it can be specified that the present strategy applies to free diffusion and is different from the one of de Sousa et al. [10] which aims at determining, in a minimal measuring time, the apparent self-diffusion coefficient (varying as a function of $\Delta)$ in case of restricted diffusion. 


\section{References}

[1] E.O. Stejskal, J.E. Tanner, J. Chem. Phys. 42 (1965) 288.

[2] C.S. Johnson, Prog. NMR Spectrosc 34 (1999) 203.

[3] B. Antalek, Concepts Magn. Reson. 14 (2002) 225.

[4] B. Blümich NMR Imaging of Materials, Clarendon Press, Oxford, 2000.

[5] J.E. Tanner, J. Chem. Phys. 52 (1970) 2523.

[6] D. Canet, Prog. NMR Spectrosc. 30 (1997) 101.

[7] F. Humbert, M. Valtier, A. Retournard, D. Canet, J. Magn. Reson. 134 (1998) 245.

[8] F. Franconi, C.B. Sonier, F. Seguin, A. Le Pape, S. Akoka, Magn. Reson. Imaging 12 (1994) 605.

[9] Y.-Q. Song, M.D. Hürlimann, C. Flaum, J. Magn. Reson. 161 (2003) 222.

[10] P.L. de Sousa, D. Abergel, J.Y. Lallemand, Chem. Phys. Lett. 342 (2001) 45 


\section{Figure captions}

Figure 1. Experiments for measuring self-diffusion coefficients. Simple PGSE sequence (1a). Stimulated echo sequence (1b). $B_{1}$ gradients (1c).

Figure 2. Plot of the function associated with the uncertainty on the self-diffusion measurement. $\mathrm{r}$ is the ratio of the amplitudes of the signal amplitudes produced by two different experiments.

Figure 3. Plot of the relative error (in module) of the measured self-diffusion coefficient of octanol ( $D=1.4210^{-6} \mathrm{~cm}^{2} / \mathrm{s}$, determined through classical ways) as a function of the ratio $S_{2} / S_{1} . S_{1}$ can be considered as arising from a reference experiment while $S_{2}$ values are obtained by means of experiments performed with increasing gradient strength.

Figure 4. Plot of the logarithm of the signal amplitude showing an acceptable decay as a function of the square of the gradient strength $\left(\right.$ in $\mathrm{G}^{2} / \mathrm{cm}^{2}$ ) for a $\mathrm{CuSO}_{4}$ doped water sample with $\mathrm{T}_{1}=2 \mathrm{~ms}$ and $\mathrm{T}_{2}=1.7 \mathrm{~ms}$. The sequence of figure $1 \mathrm{c}$ was used with $\delta=2 \mathrm{~ms}$ and $\Delta=6 \mathrm{~ms}$. The displayed data points represent an average of four different experiments (with 128 scans each). 
(a)
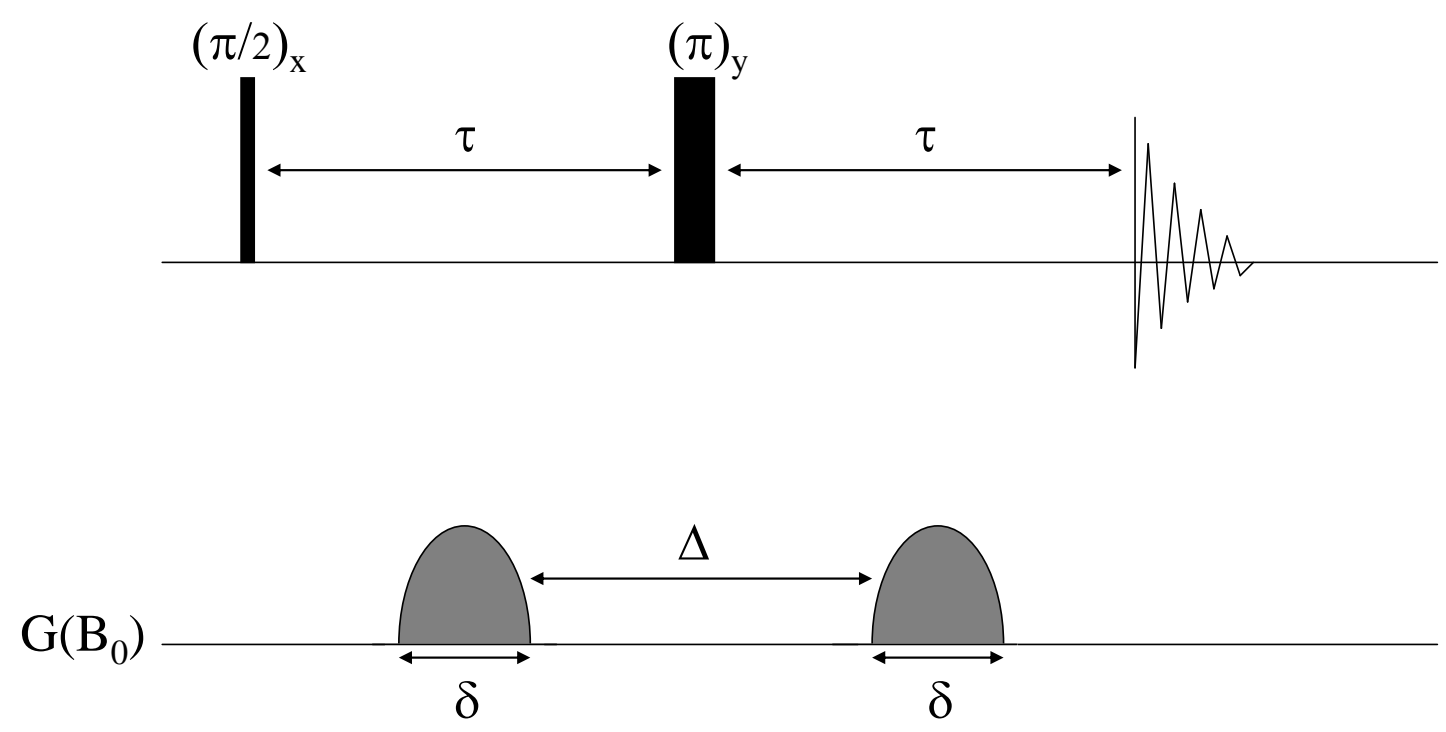

(b)
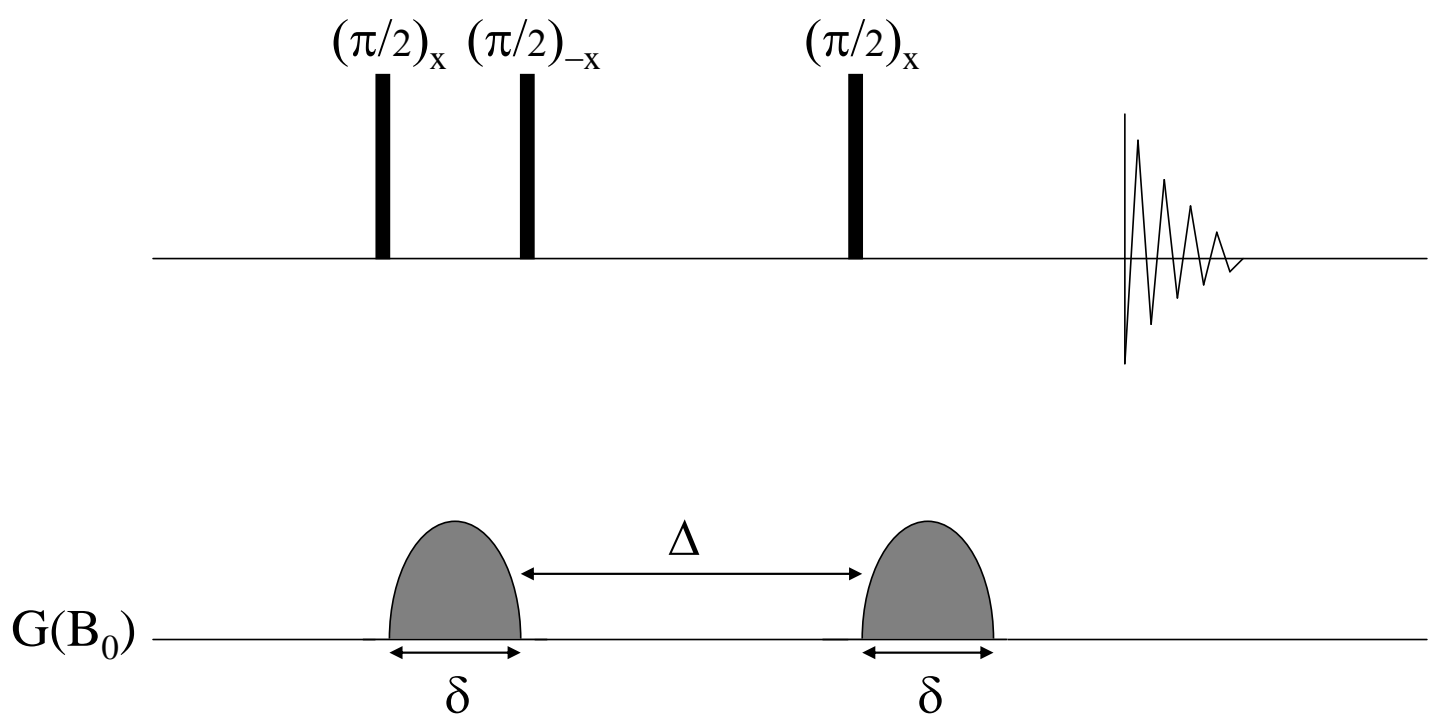

(c)

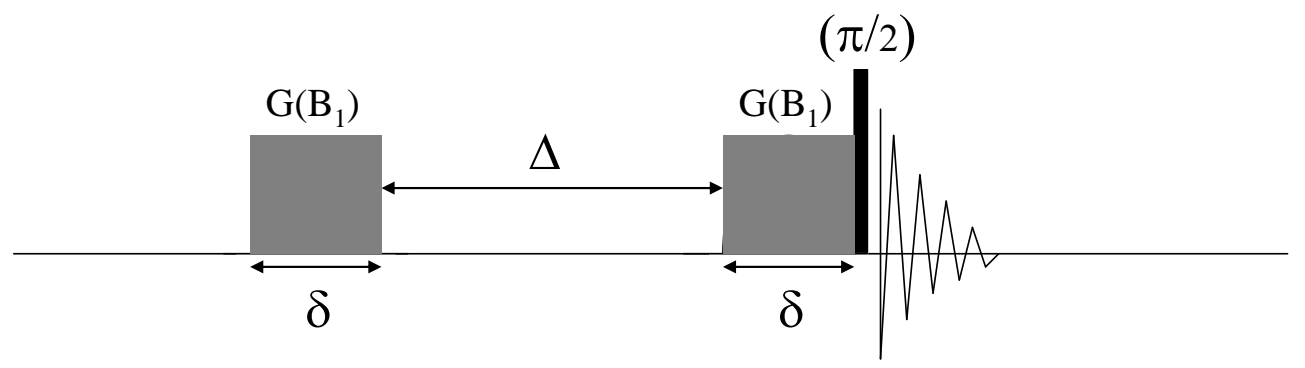

Figure 1 


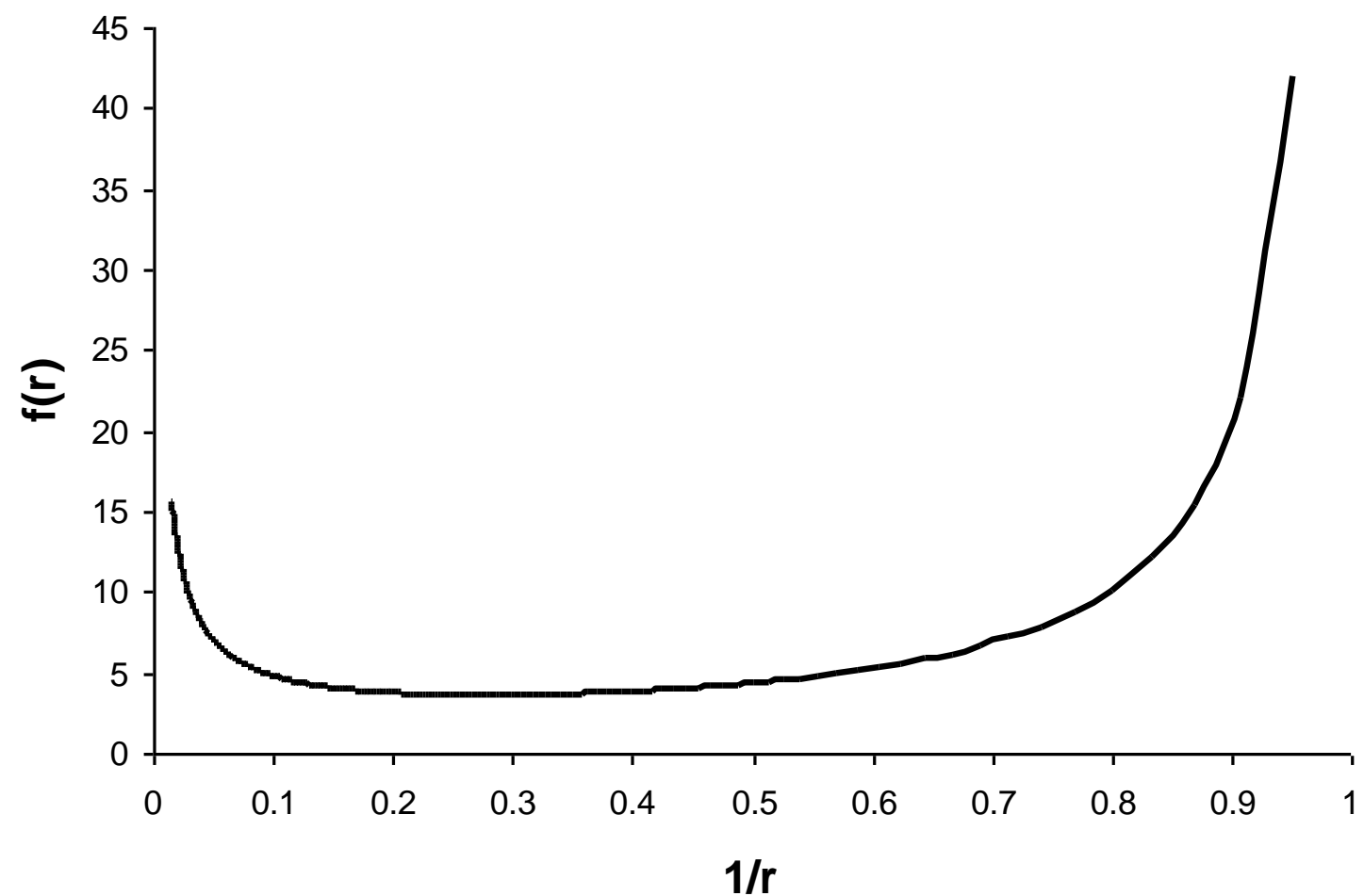

Figure 2 


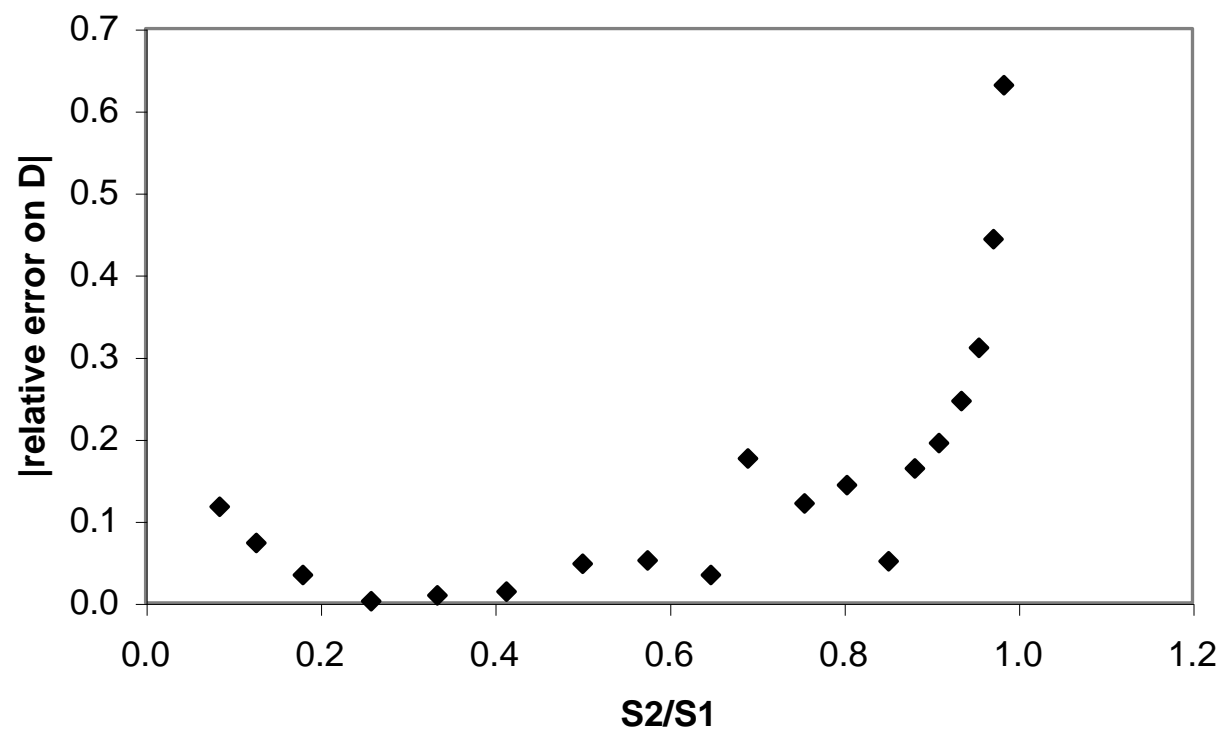

Figure 3 


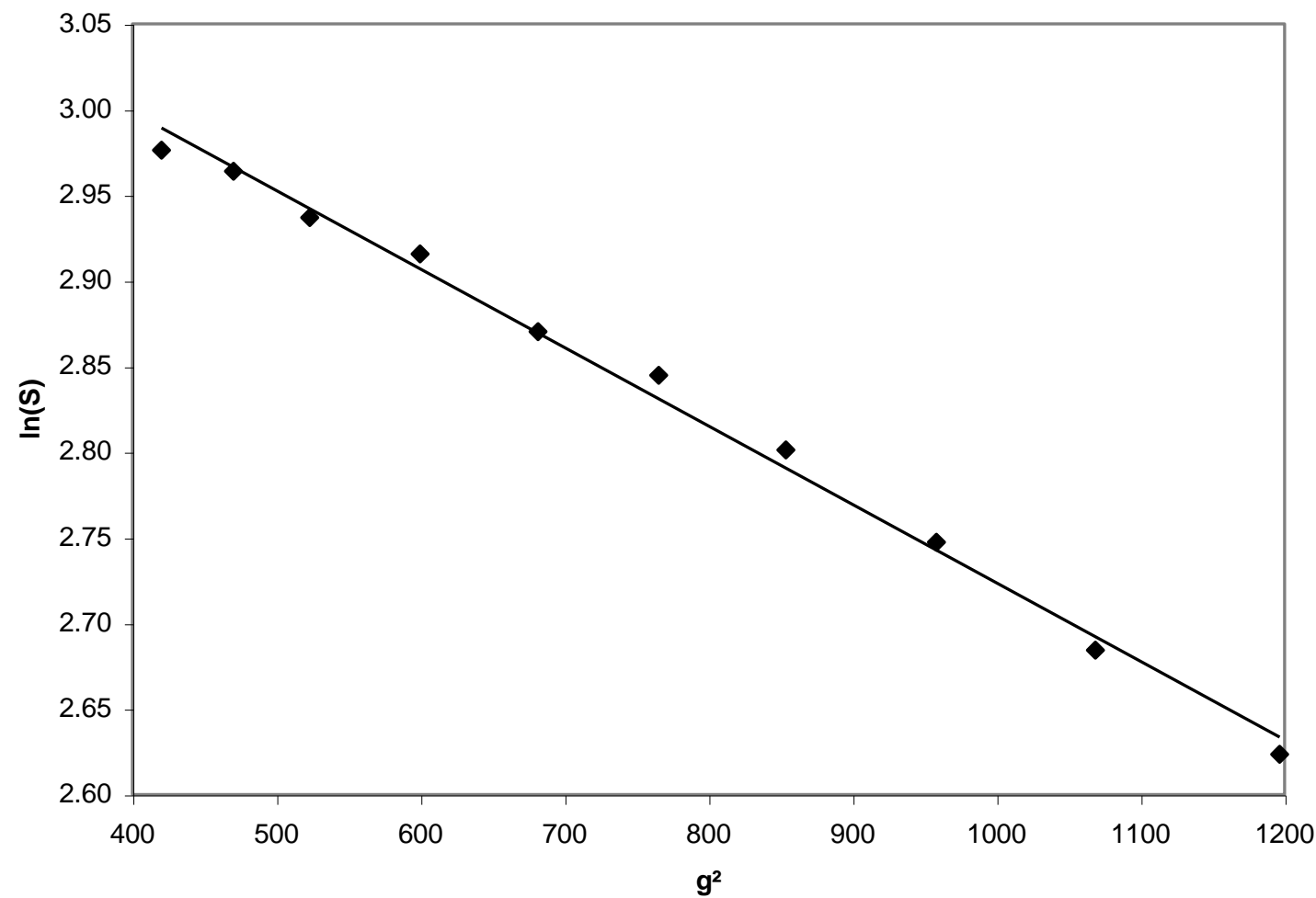

Figure 4 